\title{
Influence of light curing and sample thickness on microhardness of a composite resin
}

This article was published in the following Dove Press journal:

Clinical, Cosmetic and Investigational Dentistry

5 May 2009

Number of times this article has been viewed

\author{
Flávio HB Aguiar' \\ Kelly RM Andrade' \\ Débora AN Leite Lima' \\ Gláucia MB Ambrosano² \\ José R Lovadino' \\ 'Department of Restorative Dentistry; \\ 'Department of Social Dentistry/ \\ Statistics, Piracicaba Dental School, \\ State University of Campinas, \\ SP, Brazil
}

Correspondence: Flávio HB Aguiar Department of Restorative Dentistry, Piracicaba Dental School, State University of Campinas, Av. Limeira, 90I, Piracicaba, SP, Brazil |34|4-903

$\mathrm{Tel}+551921065340$

$\mathrm{Fax}+551921065218$

Email aguiar@fop.unicamp.br

\begin{abstract}
The aim of this in vitro study was to evaluate the influence of light-curing units and different sample thicknesses on the microhardness of a composite resin. Composite resin specimens were randomly prepared and assigned to nine experimental groups $(n=5)$ : considering three light-curing units (conventional quartz tungsten halogen [QTH]: $550 \mathrm{~mW} / \mathrm{cm}^{2}-20 \mathrm{~s}$; high irradiance QTH: $1160 \mathrm{~mW} / \mathrm{cm}^{2}-10 \mathrm{~s}$; and light-emitting diode [LED]: $360 \mathrm{~mW} / \mathrm{cm}^{2}-40 \mathrm{~s}$ ) and three sample thicknesses $(0.5 \mathrm{~mm}, 1 \mathrm{~mm}$, and $2 \mathrm{~mm})$. All samples were polymerized with the light tip $8 \mathrm{~mm}$ away from the specimen. Knoop microhardness was then measured on the top and bottom surfaces of each sample. The top surfaces, with some exceptions, were almost similar; however, in relation to the bottom surfaces, statistical differences were found between curing units and thicknesses. In all experimental groups, the $0.5-\mathrm{mm}$-thick increments showed microhardness values statistically higher than those observed for 1- and -2-mm increments. The conventional and LED units showed higher hardness mean values and were statistically different from the high irradiance unit. In all experimental groups, microhardness mean values obtained for the top surface were higher than those observed for the bottom surface. In conclusion, higher levels of irradiance or thinner increments would help improve hybrid composite resin polymerization.
\end{abstract}

Keywords: photo-polymerization, light-curing distance, light-curing units, composite resin, composite thickness, microhardness

\section{Introduction}

An important milestone in the history of modern restorative dentistry was the development of light-cured composite resins for direct use in the oral cavity. ${ }^{1}$ Improvements in both composite resin mechanical properties and light-curing devices have made possible posterior tooth restorations with greater reliability. ${ }^{2,3}$ Composite resin polymerization occurs as monomer molecules are converted into a polymer network, resulting in reduced intermolecular spaces and, consequently, shrinkage of the composite. ${ }^{4,5}$

Adequate polymerization is a crucial factor in obtaining adequate physical properties of composite resins. ${ }^{6}$ However, such variables as design and size of the light guide, light tip distance from the composite resin, power density, exposure time, shade and opacity of the composite resin, increment thickness, and material composition might interfere with the amount of radiant exposure needed to polymerize the top and bottom surfaces of a composite resin. Inadequate light curing might lead to reduced degrees of conversion, increased cytotoxicity, reduced hardness, increased pigmentation, decreased dynamic elasticity modulus, increased wear, increased marginal breakdown, and weak bonding. ${ }^{7-11}$ 
The above-mentioned variables directly affect the curing depth of the composite resin. When compared to deeper parts, the top surface of the composite resin usually receives a more adequate curing light power density during radiant exposure, because of light absorption and scattering, receive lower power density. ${ }^{11-15}$

Some studies have suggested 2-mm-thick increments. ${ }^{8,16}$ This studies were performed using the light tip very close to the resin top surface, which is quite impossible to achieve in clinical practice, mainly in deeper Class I and Class II cavities. Deficient polymerization can happen in deeper cavities, as a result of the dispersion of light energy that occurs due to the distance between the light curing tip and the first resin composite increment. ${ }^{13}$ In a deeper Class II cavity, the interface between the first increment of resin composite and the tooth structure may be less polymerized, and this interface, exposed to the oral environment, can generate marginal discolorations, restoration fractures, and resin composite and adhesive solubility, leading to microleakage and secondary caries.

Therefore, adequate polymerization is necessary to activate the physical and mechanical properties of the restorative material. ${ }^{17}$ Using light-curing units with high light irradiance could help overcome problems with light distance. ${ }^{13}$ Wang and Sang ${ }^{18}$ showed that composite resin polymerized with high irradiance significantly increased the bottom surface hardness of a composite resin.

Decreasing the resin composite increment thickness would also help with overcoming the reduction in light irradiance due to distance. According to Rueggeberg and colleagues,${ }^{19}$ light irradiance decreases greatly when the light passes through the composite resin. Prati and colleagues ${ }^{13}$ and Yap ${ }^{8}$ reported that the composite resin is capable of retaining irradiance, preventing it from reaching deeper parts of a composite resin increment. Thus, to achieve proper polymerization, resin composite increments greater than $2 \mathrm{~mm}$ should be avoided. Increments thinner than $2 \mathrm{~mm}$ were recommended by Atmadja and Bryant ${ }^{20}$ and Rueggeberg and colleagues. ${ }^{19}$

However, few studies have investigated the curing depth of composite resins in situations where the light curing tip is distant from the filling material. ${ }^{21,22}$ Therefore, further studies are needed to establish minimum composite resin thicknesses required for successful polymerization. In the present study, it was hypothesized that composite resin specimens should be thinner than $2 \mathrm{~mm}$ to ensure similar microhardness on the top and bottom surfaces, and that different light-curing units might result in different microhardness values.
The aim of this in vitro study was to evaluate the influence of the composite resin thickness and different light-curing units on the microhardness of a hybrid composite resin (Table 1), simulating a clinical situation in which the lightcuring tip was held $8 \mathrm{~mm}$ away from the top surface of the composite resin.

\section{Method and materials}

A hybrid composite resin (Filtek Z250, shade A2, 3M-ESPE Dental Products, St. Paul, MN, USA) was used to fabricate cylindrical specimens $(n=45)$ in Teflon molds $(4.0 \mathrm{~mm}$ in diameter and $0.5,1$, or $2 \mathrm{~mm}$ in height), held between two glass slabs separated by mylar matrix strips, and then pressed with a 500-g static load. The molds were randomly filled (one increment) and polymerized according to the experimental groups $(\mathrm{n}=5)$ : three light-curing units (quartz tungsten halogen [QTH] conventional $-550 \mathrm{~mW} / \mathrm{cm}^{2}-20 \mathrm{~s}$; QTH high irradiance $-1060 \mathrm{~mW} / \mathrm{cm}^{2}-10 \mathrm{~s}$; and light-emitting diodes [LED] $\left.-360 \mathrm{~mW} / \mathrm{cm}^{2}-40 \mathrm{~s}\right)$ and three sample thicknesses ( $0.5 \mathrm{~mm}, 1 \mathrm{~mm}$ and $2 \mathrm{~mm}$ ) (Table 1). The light-curing units used were XL 3000 (3M Espe, Grafenau, Germany), Elipar Freelight (3M Espe) and Optilux 501C (Demetron, Sds Kerr, Danbury, CT, USA). The irradiance was measured with the Demetron radiometer. Polymerization was carried out with the light-curing tip $8 \mathrm{~mm}$ away from the top surface of each sample; such distance was controlled using an electronic digital caliper.

Each specimen was removed from the mold and stored in a lightproof container at $37^{\circ} \mathrm{C}$ and $95 \%$ relative humidity for 24 hours. The samples surfaces were finished and polished with aluminum oxide disks Sof-Lex Pop-on (3M ESPE, St Paul, MN, USA), in decreasing order of granulation. After that, the samples were washed and microhardness considering the bottom and top surfaces of each specimen was measured using a Knoop hardness test (FM, Future Tech Corp., Tokyo, Japan) under a 25 -g load for $10 \mathrm{~s}$. Five measurements were taken considering the center area of each specimen. ${ }^{13}$ The values were obtained in micrometers and then converted into Knoop hardness number (KHN) using computer software (Excel, Microsoft Corp., Redmond, WA).

Table I Composition of the material used in this study

\begin{tabular}{ll}
\hline Resin composite & Composition \\
\hline & Filter:60\% vol \% zirconia/silica fillers with \\
& $\begin{array}{l}\text { particle size ranging from } 0.01 \text { to } 3.5 \mu \mathrm{m} \\
\text { (average } 0.6 \mu \mathrm{m} \text { ) }\end{array}$ \\
Filtek Z250 & Polymeric matrix: Bis-GMA, Bis-EMA, \\
(shade A2) & UDMA,TEGDMA \\
\hline
\end{tabular}


The results of the Knoop microhardness were analyzed by split plot analysis of variance (ANOVA) test $(p=0.05)$ and Tukey post hoc test at a 5\% significance level. Top and bottom hardness measurements were analyzed by split-plot ANOVA $(\mathrm{p}=0.05)$. The light-curing units and sample thicknesses were considered in the parcels and the factor surface (top and bottom surfaces) was considered as the sub-factor.

\section{Results}

Results concerning the microhardness test are shown in Tables 2 and 3. Significant differences were found among the light-curing units $(\mathrm{p}<0.0001)$, sample thicknesses $(p<0.0001)$, and surfaces $(p<0.0001)$, and a triple interaction among them $(\mathrm{p}<0.0001)$. Tukey post hoc test was applied for individual comparisons. Statistically significant differences were observed for the light-curing units concerning the top surface; however, no significant differences were found among the three thicknesses tested regarding all light-curing units (Table 2). The conventional showed higher hardness mean values, and was statistically different from high irradiance applied 1- and 2-mm away from the restorative material tested. The LED group showed no significant differences from the other groups at distances 0.5 and $1 \mathrm{~mm}$ (Table 2). As for the bottom surface, statistically significant differences were observed between light-curing unit distance and sample thicknesses (Table 3). In all experimental groups, microhardness values concerning the thickness of $0.5 \mathrm{~mm}$ were statistically higher than those observed for thicknesses of $1 \mathrm{~mm}$ and $2 \mathrm{~mm}$, while the 1 -mm-thick increment showed statistically higher microhardness values when compared to the 2-mm-thick one (Table 3). The conventional and LED units showed higher microhardness mean values and were statistically different from the high irradiance unit. Considering all experimental conditions, the top surface of the increments showed higher microhardness values, when compared to the bottom surface.

\section{Discussion}

This study was aimed at evaluating the influence of three sample thicknesses $(0.5,1$, and $2 \mathrm{~mm})$ and three light-curing units on microhardness of a composite resin. The abovementioned results indicate that, in deep cavities, increments thinner than $2 \mathrm{~mm}$ are more suitable for achieving adequate polymerization in bottom surface.

The top surface was less affected by the difference of radiant exposure of the light-curing units when the light tip was $8 \mathrm{~mm}$ away from the top surface. The sample thickness did not affect the top surface hardness of resin composites for all light-curing units, as expected. The light scattering due to the non-null refractive index of air (which was interposed between the light guide and the top of the specimens by the $8 \mathrm{~mm}$ spacing) not being enough to promote any difference between the light-curing units on the top surface.

None of the sample thicknesses tested affected the top surface hardness of the composite resin regarding all lightcuring units. Only for light-curing units was there statistical difference for the top surface. Conventional showed higher hardness mean values, when compared to the others, and was statistically different from high irradiance concerning thicknesses at 1 and $2 \mathrm{~mm}$. LED showed no statistically significant differences from any group in concerning thicknesses 0.5 and $1 \mathrm{~mm}$ (Table 2).

In relation to the bottom surface, there were statistical differences for the two factors assessed. The hypothesis that the composite resin increments should be thinner than $2 \mathrm{~mm}$ for adequate polymerization $(0.5 \mathrm{~mm})$ when the light-curing tip is distant from the composite resin, as in deep restorations, was confirmed. The composite resin is known to be capable of dispersing the light; thus, when light passes through the bulk of the composite, the irradiance is reduced due to light scattering caused by filler particles and resin matrix. ${ }^{11-15}$

A reduction in the thickness of the composite resin increments might help decrease such scattering effect. However, the use of $0.5-\mathrm{mm}$-thick increments to restore

Table 2 Hardness media (KHN) for the top surface

\begin{tabular}{llll}
\hline Hardness media of top surface $\mathbf{(} \pm \mathbf{S D})$ & & & \\
\hline & Sample thickness $\mathbf{( m m})$ & 2 \\
Light curving modes & 0.5 & $\mathrm{I}$ & $56.64(\mathrm{I} .54) \mathrm{Aa}$ \\
Conventional & $51.80(3.12) \mathrm{Aa}$ & $54.87(3.26) \mathrm{Aa}$ & $59.87(4.1 \mathrm{I}) \mathrm{Aa}$ \\
LED & $58.11(3.40) \mathrm{Aa}$ & $50.96(3.89) \mathrm{Aab}$ & $49.89(5.23) \mathrm{Ab}$ \\
High intensity & $51.86(4.17) \mathrm{Aa}$ & $47.76(3.14) \mathrm{Ab}$ & \\
\hline
\end{tabular}

Notes: Mean values with the same letter were not statistically different $(p<0.05)$ (same lower case letter were not statistically different for comparison among the same sample thicknesses, and same upper case letter were not statistically different for comparison among different light curing modes). 
Table 3 Hardness media for the bottom surface $(\mathrm{KHN})$

\begin{tabular}{|c|c|c|c|}
\hline \multicolumn{4}{|c|}{ Hardness media of bottom surface $( \pm S D)$} \\
\hline \multirow[b]{2}{*}{ Light curving modes } & \multicolumn{3}{|c|}{ Sample thickness $(\mathrm{mm})$} \\
\hline & 0.5 & I & 2 \\
\hline Conventional & $41.67(1.38) \mathrm{Aa}$ & $32.39(2.20) \mathrm{Ba}$ & I7.94 (I.89) Ca \\
\hline LED & $43.66(3.40) \mathrm{Aa}$ & 36.25 (3.89) $\mathrm{Ba}$ & $\mathrm{I} 6.72(4 . \mathrm{II}) \mathrm{Ca}$ \\
\hline High intensity & $34.23(4.17) \mathrm{Ab}$ & 27.34 (3.89) Bb & $9.11(5.23) \mathrm{Cb}$ \\
\hline
\end{tabular}

Notes: Mean values with the same letter were not statistically different $(p<0.05)$ (same lower case letter were not statistically different for comparison among the same sample thicknesses, and same upper case letter were not statistically different for comparison among different light curing modes).

deep cavities might be uncomfortable for patients and economically unsuitable for dentists since it (such approach) takes relatively longer. Therefore, the $0.5-\mathrm{mm}$ resin composite thickness may be used only for the deeper increments, when the increments are close to the lightcuring tip, the composite resin thickness may be increased to 1 or $2 \mathrm{~mm}$.

When the light-curing units tested were compared, conventional, statistically different from the high irradiance, showed the highest microhardness mean values, concerning all sample thicknesses (bottom surface) and light tip distances at 1 and $2 \mathrm{~mm}$ (top surface). The high irradiance presents $1010 \mathrm{~mW} / \mathrm{cm}^{2}$, but manufacturer recommends a low time of 10 seconds (total irradiance exposure: $10.1 \mathrm{~J} / \mathrm{cm}^{2}$ ), and conventional presents an irradiance of $550 \mathrm{~mW} / \mathrm{cm}^{2}$ and a light-curing time of 20 seconds (total irradiance exposure: $11 \mathrm{~J} / \mathrm{cm}^{2}$ ). The total energy is almost the same for both lightcuring times used in this study. Accordingly, in 2008 and 2009, Aguiar and colleagues ${ }^{21,22}$ the lower microhardness mean values observed for high irradiance might be due to two hypotheses: 1) the dispersion of irradiance because of the distance leveled the irradiance to that of conventional, thus the light-curing time was the difference between both; or 2) high irradiance resulted in a very fast polymerization (with a short chain length), consequently reducing elasticity modulus of the composite resin, thus decreasing the hardness. In the present study, such hypotheses seem to be evidenced by the fact that the distance between the composite resin and the light tip was large, which might reduce the irradiance for the light-curing modes mentioned above. It's possible that use high irradiance for a longer period might initiate a multitude of growth centers of polymers with higher crosslinking density, improving the physical properties of the composite resin. ${ }^{23-24}$

The LED unit showed results similar to those obtained for conventional units, considering all groups. In relation to the bottom surface, LED was statistically different from high irradiance considering the sample thicknesses tested; however, concerning the top surface, it differed from high irradiance considering the 2-mm thickness. LED has a narrow spectral range with a peak around $470 \mathrm{~nm}$, which matches the optimum absorption wavelength for the activation of the camphorquinone (CQ) photoinitiator. ${ }^{15,25}$ LED usually involve lower irradiance levels when compared to other light-curing units; however, it provides a good degree of conversion because of the high degree of overlap with the absorption spectrum of CQ. ${ }^{26}$ Therefore, it is possible that LED unit, in spite of the experimental distance and the lowest irradiance of the experimental light-curing units of this study, showed similar hardness to conventional because of the similar spectrum with CQ and the light-curing time recommended by the manufacturer (40 s).

Within the limits of this in vitro study, the use of thinner increments $(0.5 \mathrm{~mm})$, associated with an adequate lightcuring unit, might improve polymerization at the bottom portion of deep restorations, although such approach might result in a prolonged dental appointment.

\section{Conclusion}

Within the limits of this study, it can be concluded that:

1. Resin composite has the capacity of reducing light penetration and, consequently, polymerization effectiveness of the bottom surface of the sample.

2. In deep cavities, it is wise to use thinner composite resin increments to improve polymerization at the bottom surface.

3. Suitable light-curing and adequate thickness of composite resin are crucial to ensure satisfactory polymerization of composite resins, especially when used for deep restorations.

\section{Acknowledgments}

This study was supported by FAPESP (grant 02/13702-9). The authors report no conflicts of interest in this work. 


\section{References}

1. Hammesfahr PD, O'Connor MT, Wang X. Light-curing Technology: past, present, and future. Compend Contin Educ Dent. 2002;23(9 Suppl 1): $18-24$.

2. Leinfelder KF, Bayne SC, Swift Jr EJ. Packable composites: Overview and technical considerations. J Esthet Dent. 1999;11(5):234-249.

3. Manhart J, Kunzelmann KH, Chen HY, Hickel R. Mechanical properties and wear behavior of light-cured packable composite resins. Dent Mater. 2000;16(1):33-40.

4. Friedl KH, Schmalz G, Hiller KA, Märkl A. Marginal adaptation of class V restorations with and without softstart-polymerization. Oper Dent. 2000;25(1):26-32.

5. Feilzer AJ, De Gee AJ, Davidson CL. Quantitative determination of stress reduction by flow in composite restorations. Dent Mater. 1990; 6(3):167-171.

6. Knezevic A, Tarle Z, Meniga A, Sutalo J, Pichler G. Degree of conversion and temperature rise during polymerization of resin composite samples with blue diodes. J Oral Rehabil. 2001;28(6):586-591.

7. Price RB, Dérand T, Lonev RW, Andreou P. Effect of light source and specimen thickness on the surface hardness of resin composite. Am J Dent. 2002;15(1):47-53.

8. Yap AU. Effectiveness of polymerization in composite restoratives claiming bulk placement: impact of cavity depth and exposure time. Oper Dent. 2000;25(2):113-120.

9. Ferracane JL, Greener EH. Fourier transform infrared analysis of degree of polymerization of unfilled resins: methods comparison. $J$ Dent Res. 1984;63(8):1093-1095.

10. Asmussen E, Peutzfeldt A. Polymer structure of a light-cured resin composite in relation to distance from the surface. Eur J Oral Sci. 2003;111(3):277-279.

11. Asmussen E, Peutzfeldt A. Influence of specimen diameter on the relationship between subsurface depth and hardness of a light-cured resin composite. Eur J Oral Sci. 2003;111(6):543-546.

12. Sobrinho LC, de Lima AA, Consani S, Sinhoreti MA, Knowles JC. Influence of curing tip distance on composite Knoop hardness values. Braz Dent J. 2000;11(1):11-17.

13. Prati C, Chersoni S, Montebugnoli L, Montanari G. Effect of the air, dentin and resin-based composite thickness on light intensity reduction. Am J Dent. 1999;12(5) 231-234.
14. Yoon TH, Lee YK, Lim BS, Kim CW. Degree of polymerization of resin composite by different light sources. J Oral Rehabil. 2002;29(12): $1165-1173$

15. Yap AU, Wong NY, Siow KS. Composite cure and shrinkage associated with high intensity curing light. Oper Dent. 2003;28(4):357-364.

16. Emami E, Söderholm KJM. How light irradiance and curing time affect monomer conversion in light-cured resin composites. Eur J Oral Sci. 2003;111(6):536-542.

17. Tarle Z, Meniga A, Ristic M, Sutalo J, Pichler G, Davidson CL. The effect of the photopolymerization method on the quality of composite resin samples. J Oral Rehabil. 1998;25(6):436-442.

18. Wang X, Sang J. Vicker hardness of hybrid composites cured by high power curing lights [abstract]. $J$ Dent Res. 2001;80(Special Issue): 1743 .

19. Rueggeberg FA, Caughman WF, Curtis Jr JW. Effect of light intensity and exposure duration on cure of resin composite. Oper Dent. 1994;19(1):26-32.

20. Atmadja G, Bryant RW. Some factors influencing the depth of cure of visible light-ativated composite resin. Aust Dent J. 1990;35(3): 213-218.

21. Aguiar FHB, Braceiro A, Lima DA, Ambrosano GM, Lovadino JR Effect of light curing modes and light curing time on the microhardness of a hybrid composite resin. J Contemp Dent Pract. 2007;8(6):1-8.

22. Aguiar FHB, Oliveira TR, Lima DA, Ambrosano GM, Lovadino JR Microhardness of different thicknesses of resin composite polymerized by conventional photocuring at different distances. Gen Dent 2008;56(2):144-148.

23. Schneider LF, Pfeifer CS, Consani S, Prahl SA, Ferracane JL. Influence of photoinitiator type on the rate of polymerization, degree of conversion, hardness and yellowing of dental resin composites. Dent Mater. 2008;24(9):1169-1177.

24. Meng X, Yoshida K, Atsuta M. Influence of ceramic thickness on mechanical properties and polymer structure of dual-cured resin luting agents. Dent Mater. 2008;24(5):594-599.

25. Oberholzer TG, Grobler SR, Pameijer CH, Hudson AP. The effects of light intensity and method of exposure on the hardness of four lightcured dental restorative materials. Int Dent J. 2003;53(4):211-215.

26. Asmussen E, Peutzfeldt A. Influence of composition on rate of polymerization contraction of light-curing resin composites. Acta Odontol Scand. 2002;60(3):146-150.
Clinical, Cosmetic and Investigational Dentistry

\section{Publish your work in this journal}

Clinical, Cosmetic and Investigational Dentistry is an international, peer-reviewed, open access, online journal focusing on the latest clinical and experimental research in dentistry with specific emphasis on cosmetic interventions. Innovative developments in dental materials, techniques and devices that improve outcomes

\section{Dovepress}

and patient satisfaction and preference will be highlighted. The manuscript management system is completely online and includes a very quick and fair peer-review system, which is all easy to use. Visit http://www.dovepress.com/testimonials.php to read real quotes from published authors. 